\title{
Are Dentists Prescribing the Antibiotics in Justified Conditions? An Exploratory Study
}

\author{
Ahmad Liaquat ${ }^{1}$ \\ BDS, FCPS, FFD RCSI \\ Mishal Fatima Jaffery ${ }^{2}$ \\ BDS \\ Mahwish Usman ${ }^{3}$ \\ BDS \\ Tahmasub Faraz Tayyab ${ }^{4}$ \\ BDS, FCPS \\ Tooba Saeed ${ }^{5}$ \\ BDS, FCPS \\ Ansa Naheed ${ }^{6}$ \\ MBBS
}

OBJECTIVE: Antibiotic prescription is a common practice among dental practitioners. Unjustified antibiotic prescription is leading to antibiotic resistance. The purpose of this survey is to analyze the most commonly prescribed antibiotics, conditions in which antibiotics are being prescribed, either the dental surgeons prescribe the antibiotics in the conditions where they are not recommended and awareness of antibiotic resistance among the dental practitioners of Lahore.

METHODOLOGY: The study aimed to identify the prevalence of unjustified prescription of antibiotics so we can take measures to teach dental students about this wrong and unjustified prescription in undergraduate studies. It was an observational crosssectional study. Among dental practitioners of Lahore, 380 were selected through a non-probability convenience sampling technique. Standardized; a previously validated questionnaire was used containing 18 questions, about the most commonly prescribed antibiotics, conditions where antibiotics are indicated, and antibiotic resistance. Data was coded in SPSS version 20. RESULTS: It showed the studied sample of dental practitioners tends towards the over-prescription of antibiotics.

CONCLUSION: Dentists should prescribe antibiotics only according to the latest guidelines, where it is indicated. It should not be a first-line treatment modality.

KEYWORDS: antibiotic resistance awareness, unjustified antibiotic prescription

HOW TO CITE: Liaquat A, Jaffary MF, Usman M, Tayyab TF, Saeed T, Naheed A . Are dentists prescribing the antibiotics in justified conditions? an exploratory study. J Pak Dent Assoc 2020;29(3):120-123.

DOI: https://doi.org/10.25301/JPDA.293.120

Received: 15 December 2019, Accepted: 28 April 2020

\section{INTRODUCTION}

$\mathrm{M}$ ost human orofacial infections originate from odontogenic infections and prescribing antibiotics has become a ubiquitous phenomenon. ${ }^{1-5}$ Antibiotic prescription is a common practice among dental practitioners. This is leading to antibiotic resistance in our population and other health issues related to the over-prescription of antibiotics. ${ }^{6-8}$ The World Health

1. Assistant Professor, Department of Oral \& Maxillofacial Surgery, University College of Medicine \& Dentistry, University of Lahore.

2. House officer, Department of Oral \& Maxillofacial Surgery, University College of

Medicine \& Dentistry, University of Lahore.

3. House officer, Department of Oral \& Maxillofacial Surgery, University College of Medicine \& Dentistry, University of Lahore.

4. Assistant Professor, Department of of Oral \& Maxillofacial Surgery, University College of Medicine \& Dentistry, University of Lahore.

5. Senior registrar, Department of Oral \& Maxillofacial Surgery, University College of Medicine \& Dentistry, University of Lahore.

6. FCPS Resident, Department of East Medical Ward, King Edward Medical University, Lahore.

Corresponding author: "Dr. Ahmad Liaquat" < ahmadliaquat@ hotmail.com >
Organization (WHO) has recognized the inappropriate, indiscriminate, and irrational use of antibiotics leading to antibiotic resistance as a global problem. ${ }^{2,5,7,8}$

Antibiotics have emerged as a boon to humanity and this advancement has led to a better quality of life along with an overall reduction in morbidity and mortality. These are chemical substances that are capable of destroying and inhibiting the growth of specific microorganisms, such as infectious bacteria and fungi. Dental infections are polymicrobial in nature. The majority of orofacial infections require both systemic and local management. ${ }^{9-12}$ Systemic management is mostly by antibiotics, and hence, these antibiotics are pharmacotherapeutic adjuncts prescribed by dentists. $^{1-13-15}$

Inappropriate, indiscriminate, and irrational use of antibiotics has led to the development of antibiotic resistance. Even more alarming is the rate at which bacteria develop resistance. ${ }^{16-18}$ Microorganisms exhibiting resistance to new 
Liaquat A/ Jaffary MF/ Usman M/

Tayyab TF/ Saeed T/ Naheed A

drugs often are isolated soon after the drugs have been introduced. The main reason behind antibiotic resistance is due to over-prescription by the health-care personnel, improper use by patients, and also due to the resistance developed by the bacteria. ${ }^{2-4,19-20}$ There is a significant relationship between the increase of antibiotic resistance and utilization, with higher resistance levels in bacteria isolated from areas of high antibiotic utilization. ${ }^{1,3}$ Dentists prescribe between $7 \%$ and $11 \%$ of all common antibiotics. ${ }^{5}$ As per the National Center for Disease Control and Prevention, approximately one-third of all outpatient antibiotic prescriptions are unnecessary. ${ }^{5}$ Dentistry's contribution to antibiotic resistance is unknown. With increasing prescription of antibiotics and bacterial resistance, newer drug combinations are being introduced. Hence, keeping in the mind trend of prescribing practices in dentistry, it is required to assess the knowledge and practice among dental practitioners. ${ }^{1,3,5}$ Limited studies have assessed the antibiotic prescription pattern and knowledge regarding the development of resistance among dentists in India. Hence, the study was conducted with the objective to assess dental practitioner's knowledge and practices regarding antibiotic prescription and development of resistance..$^{7-10}$

Antimicrobial resistance has been identified as one of the greatest threats to future human health with an increasing number of resistant microbial strains reported each year across both human and animal populations in developed and developing countries. ${ }^{21,22}$ Policymakers, health organizations, and research institutes have called for tighter control over their distribution and use in society ${ }^{5,6}$ with an emphasis on front-line antibiotic prescribers and dispensers ${ }^{7}$ While efforts have been sustained over many years to promote the 'rational use of drugs', for example through the WHO's International Network on the Rational Use of Drugs program (INRUD), the scale of antibiotic use appears to be escalating. ${ }^{15-17}$

An increase in antibiotic resistance (ABR) worldwide, specifically in developing countries, necessitates the need to pay attention to antibiotics prescription and knowledge and awareness of Antibiotic Resistance among dental practitioners. ${ }^{1-2}$ In May 2015, the World Health Assembly reached an agreement to tackle the menace of Antibiotic Resistance globally, and the first objective was to increase Antibiotic Resistance awareness and understanding. ${ }^{3}$ Antibiotics are medicines formulated for treatment or prevention of bacterial infections, administered to patients based on the prescription of certified health care professionals. In developing countries, antibiotics can be readily purchased without any control; such countries usually experience more cases of antibiotic resistance, in contrast to what occurs in western nations where tight regulations of antibiotic use are in place. ${ }^{4-7}$
Are dentists prescribing the antibiotics in justified conditions? An exploratory study

\section{METHODOLOGY}

An observation study that followed a cross-sectional study design was conducted. Among dental practitioners of Lahore, 380 were selected through a non-probability convenience sampling technique. The sample size was determined using this formula. ${ }^{3}$

$$
\text { Sample Size }=\frac{\mathrm{Z}_{1} \infty / 2^{2} \mathrm{SD}^{2}}{\mathrm{~d}^{2}}
$$

standardized, previously validated questionnaire was used containing 18 questions, about the most commonly prescribed antibiotic, conditions where antibiotics are indicated and antibiotic resistance. The questionnaire was used in English

as such. Data was coded in SPSS version 20.

\section{RESULTS}

Majority dentists are prescribing antibiotics in conditions where they are not needed. Amoxicillin is commonly prescribed Antibiotic. Most dentists prefer prescribing antibiotics for 3 days. Awareness about antibiotic resistance is adequate. A considerable group of the dentist is not aware of guidelines regarding antibiotics prescription.

Table- 1 shows that dentists are prescribing antibiotics in conditions where they are not indicated at all. In general,

Table 1: Conditions in which antibiotics are prescribed $(\mathrm{N}=380)$

\begin{tabular}{|l|l|c|}
\hline Conditions & \multicolumn{2}{|l|}{ Dentists prescribe the antibiotics } \\
& Yes & $20.26 \%$ \\
\hline Localized intra-oral swelling & $79.74 \%$ & $26.05 \%$ \\
\hline Pericoronitis & $73.95 \%$ & $37.37 \%$ \\
\hline Simple extraction & $62.63 \%$ & $32.11 \%$ \\
\hline Apical periodontitis & $67.89 \%$ & $71.84 \%$ \\
\hline Dry socket & $28.16 \%$ & $37.11 \%$ \\
\hline Reversible pulpitis & $62.89 \%$ & $37.37 \%$ \\
\hline Irreversible pulpitis & $62.63 \%$ & \\
\hline
\end{tabular}

more than $60 \%$ of dentists are prescribing antibiotics in conditions where they have no role.

According to the figure-1, the most commonly prescribed antibiotic is co-amoxiclav, which is a secondline drug. Whereas first-line drugs, amoxicillin is only $20.25 \%$ prescribed. The results indicate inappropriate practice among dental practitioners.

Most dentists are aware of the causes of antibiotic resistance and they claim that they take a proper history 
Liaquat A/ Jaffary MF/ Usman M/

Tayyab TF/ Saeed T/ Naheed A

Figure 1: Most commonly prescribed antibiotics ( $\mathrm{N}=380)$

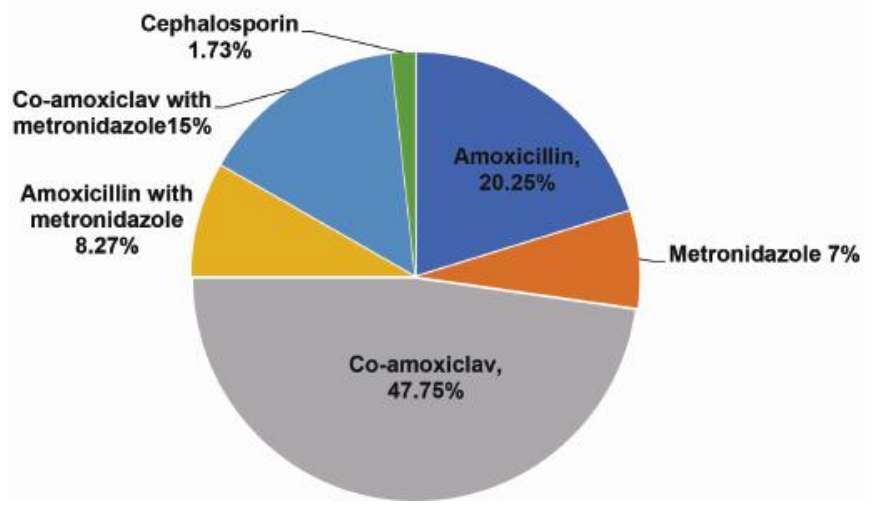

Table 2: Antibiotics resistance and its factors $(\mathrm{N}=360)$

\begin{tabular}{|l|l|l|l|}
\hline No. & Questions & YES & NO \\
\hline 1 & Are you aware of the term “Antibiotic resistance" & $74.47 \%$ & $25.53 \%$ \\
\hline 2 & $\begin{array}{l}\text { Do you know Self-medication cause drug } \\
\text { resistance }\end{array}$ & $58.16 \%$ & $41.84 \%$ \\
\hline 3 & $\begin{array}{l}\text { Do you take history about antibiotics used by the } \\
\text { patient in past 1 week before prescribing } \\
\text { antibiotics }\end{array}$ & $54.47 \%$ & $45.53 \%$ \\
\hline 4 & $\begin{array}{l}\text { Do you advise your patients to adhere to dose } \\
\text { regimen }\end{array}$ & $64.47 \%$ & $35.53 \%$ \\
\hline
\end{tabular}

Figure 2: Reasons for antibiotics prescription

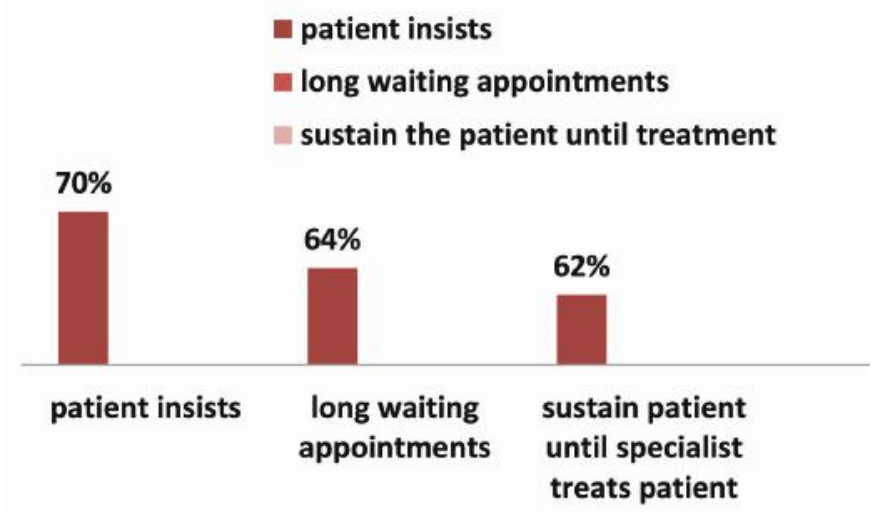

about the last course of antibiotics and also advise patients to adhere to antibiotic dose regimen.

Dentists claim that the most common reason for antibiotic prescription patient's insistence and more than $60 \%$ of dentists claim that they prescribe antibiotics due to long waiting appointments and to sustain the patient until specialist treats the patient.

\section{DISCUSSION}

In our study most commonly prescribe antibiotic was Co-amoxiclav (47.75\%). In a study conducted by
Are dentists prescribing the antibiotics in justified conditions? An exploratory study

Sapna Konde et al. in India in the sample of 100 BDS and 100 MDS, amoxicillin was the most commonly prescribed antibiotic, $86 \%$ of BDS and $70 \%$ of MDS prescribe Amoxicillin. ${ }^{5}$ Co-amoxiclav is a second line Antibiotic according to the current guidelines ${ }^{7-9}$, a large number of dentists are prescribing it in Lahore.

Salako et al. conducted a study in Kuwait in a sample of 200 dental practitioners which shows $78.57 \%$ of dentists are prescribing antibiotics in conditions like a dry socket, pericoronitis, simple extraction, and localized intraoral swelling. ${ }^{16}$ In our study $58.25 \%$ dentists are prescribing antibiotics where they aren't indicated.

In our study, $58.25 \%$ dentists are prescribing antibiotics where they are not indicated. According to our study, $74.47 \%$ of dentists are aware of antibiotic resistance. A study conducted in France and Scotland by D.Nathwani in a sample of 300 dentists, $95 \%$ of junior doctors and $63 \%$ of senior doctors are considerate about Antibiotic Resistance. ${ }^{19-20}$ There should be Antibiotic awareness programs. There should be our own antibiotic prescription guidelines in Pakistan. There should be strict rules about purchasing the Antibiotics in pharmacy. Antibiotics shouldn't be over the counter sold the drug. Compliance towards the guidelines should be monitor via policy. Our relative limitations were time constraints and Initial cross-sectional non-probability convenience sampling technique was used.

\section{CONCLUSION}

Results are indicative that the studied sample of dental practitioners tends the over-prescription of antibiotics. Dentists should prescribe Antibiotics only according to the latest Guidelines, where it is indicated. It shouldn't be first-line treatment modality. ${ }^{21}$

\section{CONFLICT OF INTEREST}

None declared

\section{REFERENCES}

1. Davies J, Davies D. Origins and evolution of antibiotic resistance. Microbiol Mole Biol reviews. 2010;74:417-33.

https://doi.org/10.1128/MMBR.00016-10

2. http://www.sdcep.org.uk/wp-content/uploads/2016/03/SDCEPDrug-Prescribing-for-Dentistry-3rd-edition.pdf

3. Charan J, Biswas T. How to calculate sample size for different study designs in medical research? Indian J Psychologi Medi.2013;35:121 https://doi.org/10.4103/0253-7176.116232

4. Jain A, Bhaskar DJ, Gupta D, Yadav P, Dalai DR, Jhingala V, Garg Y, Kalra M. Drug prescription awareness among the 3 rd year and 
Liaquat A/ Jaffary MF/ Usman M/ Tayyab TF/ Saeed T/ Naheed A

final year dental students: A cross-sectional survey. J Indian Assoc Public Health Denti. 2015;13:73

https://doi.org/10.4103/2319-5932.153598

5.Konde S, Jairam LS, Peethambar P, Noojady SR, Kumar NC. Antibiotic overusage and resistance: A cross-sectional survey among pediatric dentists. J Indian Soci Pedodont Prevent Denti.2016;34:145. https://doi.org/10.4103/0970-4388.180444

6. Salako NO, Rotimi VO, Adib SM, Al-Mutawa S. Pattern of antibiotic prescription in the management of oral diseases among dentists in Kuwait. J denti. 2004;32:503-09.

https://doi.org/10.1016/j.jdent.2004.04.001

7. Pulcini C, Williams F, Molinari N, Davey P, Nathwani D. Junior doctors' knowledge and perceptions of antibiotic resistance and prescribing: a survey in France and Scotland. Clinical Microbiol infecti. 2011;17:80-7.

https://doi.org/10.1111/j.1469-0691.2010.03179.x

8. Andersson L, Andreasen JO, Day P, Heithersay G, Trope M, DiAngelis AJ, Kenny DJ, Sigurdsson A, Bourguignon C, Flores MT, Hicks ML. International Association of Dental Traumatology guidelines for the management of traumatic dental injuries: 2 . Avulsion of permanent teeth. Dent Traumatol. 2012;28:88-96.

https://doi.org/10.1111/j.1600-9657.2012.01125.x

9. Huang Y, Gu J, Zhang M, Ren Z, Yang W, Chen Y, Fu Y, Chen X, Cals JW, Zhang F. Knowledge, attitude and practice of antibiotics: a questionnaire study among 2500 Chinese students. BMC Medi Educ. 2013;13:163.

https://doi.org/10.1186/1472-6920-13-163

10. Segura-Egea JJ, Velasco-Ortega E, Torres-Lagares D, VelascoPonferrada MC, Monsalve-Guil L, Llamas-Carreras JM. Pattern of antibiotic prescription in the management of endodontic infections amongst Spanish oral surgeons. Inter Endod J.2010;43:342-50. https://doi.org/10.1111/j.1365-2591.2010.01691.x

11. Baskaradoss JK, Alrumaih A, Alshebel A, Alfaqih A, Aleesa M, Alkhashan S, Altuwaijri M. Pattern of antibiotic prescription among dentists in Riyadh, Saudi Arabia. J Investigat Clini Denti. 2018:e12339. https://doi.org/10.1111/jicd.12339

12. El-Kholey KE, Wali O, Elkomy A, Almozayen A. Pattern of Antibiotic Prescription for Oral Implant Treatment Among Dentists in Saudi Arabia. Implant denti. 2018;27:317.

https://doi.org/10.1097/ID.0000000000000748

13. Marra F, George D, Chong M, Sutherland S, Patrick DM. Antibiotic prescribing by dentists has increased: Why? J Am Dent Assoc. 2016;147:320-27.

https://doi.org/10.1016/j.adaj.2015.12.014

14. Prior M, Elouafkaoui P, Elders A, Young L, Duncan EM, Newlands
Are dentists prescribing the antibiotics in justified conditions? An exploratory study

R, Clarkson JE, Ramsay CR. Evaluating an audit and feedback intervention for reducing antibiotic prescribing behaviour in general dental practice (the RAPiD trial): a partial factorial cluster randomised trial protocol. Implementa Sci. 2014;9:50.

https://doi.org/10.1186/1748-5908-9-50

15. Dana R, Azarpazhooh A, Laghapour N, Suda KJ, Okunseri C. Role of Dentists in Prescribing Opioid Analgesics and Antibiotics: An Overview. Dent Clini North Am.2018;62:279-94.

https://doi.org/10.1016/j.cden.2017.11.007

16. Anu V, Harshamol S, Helena T, Hannah PD, Gokila R, Manomani H. Paediatricians Cognizance About The Deleterious Effect Of Antibiotics And Dental Caries-A Preliminary Study. Int J Pharmaceutical Sci Res. 2018;9:708-11.

17.Roberts RM, Bartoces M, Thompson SE, Hicks LA. Antibiotic prescribing by general dentists in the United States, 2013. J Am Dent Assoc. 2017;148:172-8.

https://doi.org/10.1016/j.adaj.2016.11.020

18. Zhuo A, Labbate M, Norris JM, Gilbert GL, Ward MP, Bajorek BV, Degeling C, Rowbotham SJ, Dawson A, Nguyen KA, HillCawthorne GA. Opportunities and challenges to improving antibiotic prescribing practices through a One Health approach: results of a comparative survey of doctors, dentists and veterinarians in Australia. BMJ open. 2018;8:e20439.

https://doi.org/10.1136/bmjopen-2017-020439

19. Stein K, Farmer J, Singhal S, Marra F, Sutherland S, Quiñonez C. The use and misuse of antibiotics in dentistry: A scoping review. The J Am Dent Assoc. 2018;149:869-84

https://doi.org/10.1016/j.adaj.2018.05.034

20. Koppen L, Suda KJ, Rowan S, McGregor J, Evans CT. Dentists' prescribing of antibiotics and opioids to Medicare Part D beneficiaries: medications of high impact to public health. J Am Dent Assoc. 2018;149:721-30.

https://doi.org/10.1016/j.adaj.2018.04.027

21. Suda KJ, Henschel H, Patel U, Fitzpatrick MA, Evans CT. Use of antibiotic prophylaxis for tooth extractions, dental implants, and periodontal surgical procedures. InOpen forum infectious diseases 2018 (Vol. 5, No. 1, p. ofx250). US: Oxford University Press. https://doi.org/10.1093/ofid/ofx250

22. Bird L, Landes D, Robson T, Sturrock A, Ling J. Higher antibiotic prescribing propensity of dentists in deprived areas and those with greater access to care in the North East and Cumbria, UK. Bri Dent J. 2018;225:517.

https://doi.org/10.1038/sj.bdj.2018.752 